situations where this is not apparent. However, I think it is most unfortunate that he invents the term 'allele-specific linked polymorphism', when the discipline of genetics already has the more appropriate term of linkage disequilibrium. It is the job of the series editor to ensure that the contributions are appropriately integrated with general biochemistry and genetics, and this includes using the accepted nomenclature. For maximum reliability in prenatal diagnosis using linkage analysis it is important to study additional family members, ideally an affected person, even if one is dealing with an extreme linkage disequilibrium like sickle and the HpaI site; this point should have been emphasised.

The final contribution by $\mathbf{M} \mathbf{P}$ Wickens and R A Laskey reviews eukaryotic transcription assays, particularly the expression of cloned genes in cellfree systems and in micro-injected Xenopus oocytes. Here again there is a satisfactory combination of methodological details and experimental results which gives the reader a real feel for the exciting new work on gene regulation.

Overall, the book is well set out with lots of sub-headings, useful tables of contents, and diagrams where appropriate. It is well up to date; the last contribution, for example, quotes 291980 references and a few 'in press' for 1981. It will be of interest to those who seriously want to learn more about the recombinant DNA revolution.

Marcus Pembrey

\section{Dentistry in the Interdisciplinary Treatment of Genetic Diseases}

Birth Defects: Original Article Series. Volume XVI, No 5 . Edited by Carlos F Salinas and Ronald J
Jorgenson. (Pp xvii +200 ; figures + tables.) New York: Alan R Liss. 1980.

There is no real need for every geneticist to buy each volume in the Birth Defects: Original Article Series but it is a valuable asset for central medical libraries in each region to have a full series. The latest volume contains the proceedings of a symposium which served as a meeting ground for dentists and geneticists. A good deal of the book explores the role of the dentist in genetic counselling and his relationship with the geneticist in preventing dental disease, especially where more widespread dysmorphic features are present. Above all, the emphasis is on the combined participation of the dentist and geneticist in the craniofacial team. Close collaboration of this nature is rare in this country. Perhaps the established tradition in the USA of the dentist as dysmorphologist has helped the relationship. Many of the papers make interesting but not essential reading. Gorlin writes an entertaining article on perception and Witkop unfolds the history of genetics in dentistry. The chapters the geneticist will most want to refer to are those of Salinas on the objective evaluation of the craniofacies, the chapter on the Birth Defects Information Service by Buyse, and the one on numerical taxonomy by Preus. There is also a useful chapter on diagnostic problems but there are no case reports on individual families with genetic disease.

Perhaps this volume can best be used as a probe (a pertinent word) to identify those dentists who are interested in the syndromes of the head and neck and to persuade them to join the geneticist at a combined and regular dysmorphology meeting.

M BARAITSER 